\title{
Expansão da Fronteira Agropecuária do Oeste Paulista para a Amazônia: A Trajetória dos Negócios da Família Ometto e Seus Desdobramentos no Mato Grosso.
}

\author{
Expansion of Agricultural Frontier From West of São Paulo On Amazon: The Trajectory \\ of the Family Ometto and Its Consequences in Mato Grosso
}

Armando Wilson Tafner Junior ${ }^{1}$ Fábio Carlos da Silva²

\begin{abstract}
RESUMO: A expansão da fronteira agropecuária brasileira para a Amazônia, na segunda metade do século XX, ocorreu de forma direcionada, privilegiando os interesses do grande capital e deixando à margem uma população, de diferentes etnias, que já se encontrava instalada na Região. A política de incentivos fiscais implementada pela Superintendência do Desenvolvimento da Amazônia - SUDAM, a partir de 1966, favoreceu a expansão dos negócios de famílias de fazendeiros e empresários rurais do Centro-Sul do Brasil, principalmente de São Paulo, que adquiriram milhares de hectares de terras devolutas estaduais, a preços irrisórios, principalmente nos estados cortados pelas rodovias Belém-Brasília e CuiabáPortoVelho. Dentre os projetos pioneiros aprovados pela SUDAM, o de maior magnitude fundiária foi o da Agropecuária Suiá-Missu S/A, até então o maior latifúndio da América Latina pertencente à família Ometto, residente no Estado de São Paulo. O artigo analisa a trajetória dos negócios da família Ometto do interior de São Paulo para o estado do Mato Grosso, e os principais efeitos e impactos sociais e econômicos dos negócios da família no Mato Grosso.
\end{abstract}

PALAVRAS CHAVE: Fronteira agropecuária; Amazônia; Família Ometto

ABSTRACT: The expansion of Brazilians agricultural frontier to the Amazon, in the second half of the twentieth century was directed manner, favoring the interests of big capital and leaving aside a population of different ethnic groups, which was already installed in the region. The policy of tax incentives implemented by the Superintendency for Development of Amazonia - SUDAM, from 1966, favored the expansion of the business of family farmers and rural entrepreneurs in the CenterSouth of Brazil, especially in São Paulo, who acquired thousands of acres of state public lands, at ridiculous prices, especially in the states cut the highways BelémBrasília and Cuiabá-Porto Velho. Among the pioneering projects approved by SUDAM, the largest land was the magnitude of Agriculture Suiá Missu-S/A, until then the largest landlordism in Latin America belonging to Ometto family, residing in the State of São Paulo. The article analyzes the trajectory of the business of the Ometto family in the countryside of São Paulo for the state of Mato Grosso business, and the main effects and social and economic impacts of the family business in Mato Grosso.

Key Words: Agricultural frontier; Amazon; Ometto Family

\section{Código Jel: N56}

\footnotetext{
1 Doutorando em Desenvolvimento Socioambiental pelo Núcleo de Altos Estudos Amazônicos da Universidade Federal do Pará - NAEA/UFPA

2 Professor Associado do Núcleo de Altos Estudos Amazônicos da Universidade Federal do Pará NAEA/UFPA
}

Revista de Estudos Sociais | Ano 2014, N. 31, V. 16, Pag. 97 


\section{INTRODUÇÃO}

A expansão territorial em direção ao Oeste do Brasil teve início com os bandeirantes no fim do século XVI, que tinham por objetivo explorar novos horizontes em busca de metais preciosos. Com a chegada dos imigrantes europeus no final do século XIX, principalmente italianos, a expansão da fronteira econômica no Brasil deveu-se às atividades agrícolas. O café e a cana-de-açúcar no período referido eram os principais produtos cultivados pelos proprietários de terra em São Paulo. À medida em que a necessidade de novas terras para o cultivo aumentava, as plantações iam se direcionando para - Oeste. A partir da década de 1960 a fronteira agropecuária atinge com intensidade a Amazônia. A "ocupação" do vazio demográfico e a busca pela integração econômica de regiões afastadas do centro industrial, fez com que o governo incentivasse os grandes capitalistas a expandir seus negócios para a região amazônica.

O estado do Mato Grosso foi o estado da Amazônia que obteve o maior número de projetos aprovados pelo governo federal, entre 1966 e 1979, para promover a agropecuária e a colonização da região.

Entre os capitalistas que submeteram projetos agropecuários com 0 intuito de receber incentivos fiscais fornecidos pelo governo federal, estava a família Ometto. Esta família, de origem italiana, é atualmente proprietária de usinas produtoras de açúcar e álcool no interior de São Paulo. Os patriarcas da família vieram para o interior de São Paulo para trabalharem nas fazendas de café, como tantos outros imigrantes italianos que abandonaram sua terra natal para viverem na América. Conseguiram se estabelecer no Brasil, montaram um grande patrimônio no estado de São Paulo e expandiram seus negócios para a Amazônia na década de 1960.

Este artigo procura mostrar os motivos que fizeram com que a família Ometto viesse para o Brasil, de que forma conseguiram se estabelecer no estado de São Paulo e ampliar os negócios para a Amazônia. Posteriormente explica como se deu a colonização no estado do Mato Grosso, e por fim, analisa as modificações sócio-econômicas que as empresas comandadas pelo Grupo Ometto provocaram na região.

\section{OS MOTIVOS QUE ORIGINARAM A EMIGRAÇÃO ITALIANA}

O continente europeu durante o século XIX sofreu uma grande aceleração do crescimento demográfico. Entre 1815 e 1914 a população européia duplicou (EMMI, 2008). Isso ocorreu devido às melhorias na saúde, condições de higiene minimamente satisfatórias, o surgimento da vacina e o aumento da conscientização da população. Com isso, houve uma diminuição significativa da taxa de mortalidade, ocasionando o crescimento natural da 
população. Esse fator, juntamente com a chegada da Segunda Revolução Industrial, fez com que o sistema capitalista passasse por uma mudança de paradigma, - do capitalismo concorrencial para o imperialismo - que, mesmo com os avanços tecnológicos das indústrias, não foi capaz de absorver grande parte do excedente demográfico.

Com isso a Europa passava por dificuldades devido aos baixos salários, alto índice de desemprego, uma alta no preço dos alimentos e um pauperismo crônico. A intensificação das emigrações européias, principalmente a partir da segunda metade do século XIX, foi o resultado das condições de vida da população que, na época, eram precárias. As migrações européias transoceânicas, direcionadas ao continente americano, tiveram em sua origem, a reestruturação do capitalismo que possibilitou uma possível concentração de renda, deixando um grande contingente populacional à margem do sistema (HOBSBAWN, 1977).

É certo que os europeus já estavam na América desde o século XVI devido à expansão marítima em busca de novas terras para promover a exploração, mas o movimento das emigrações européias transoceânicas a partir da segunda metade do século XIX aparece com grande magnitude.

Klein (2000) define as emigrações européias em quatro momentos: $1^{\circ}$ ) velha migração, que se estende do início do século $\mathrm{XVI}$ até a primeira metade do século XIX; $2^{\circ}$ ) o período que vai de 1850 até a Primeira Guerra Mundial; 3) o período que tem início com o fim da Primeira Guerra Mundial até o início da Segunda Grande Guerra; e por fim, o último período que começa no pós-guerra e segue até os dias atuais. Para nós interessa o segundo período de Klein, no qual um grande contingente de europeus se deslocou para outros continentes, e que trouxe ao Brasil uma grande quantidade de imigrantes italianos, dentre estes a família Ometto, vinda da Itália para o Estado de São Paulo, no ano de 1887.

A penúltima década do séc. XIX vai marcar um momento importante na migração européia. Nos fins do séc. XIX e, sobretudo nas duas primeiras décadas do séc.XX, assistiu-se uma intensificação do movimento migratório. Esse período ficou conhecido como o da Grande Migração, movimento populacional que teve como condicionante o avanço tecnológico (energia a vapor, cabo telegráfico transatlântico, ligações ferroviárias), possibilitando aos europeus informações sobre as condições de emprego e de acesso à terra nos países americanos. Nessa época, a terra na Europa era cara e a mão-de-obra barata. $O$ inverso se dava nos países americanos, o que motivava a busca por essas terras (EMMI, 2008 p.60).

Revista de Estudos Sociais | Ano 2014, N. 31, V. 16, Pag. 99 
Neste período chegaram às Américas cerca de 31 milhões de imigrantes, tendo a maioria como destino os Estados Unidos e o Brasil. Dentre estes cerca de 14 milhões eram italianos (KLEIN, 2000). Nessa época os governantes incentivaram a emigração, pois o crescimento demográfico foi intenso devido a pressão sobre a terra exercida pela oferta de mão-de-obra excedente, que cresceu sem que existisse qualquer tipo de planejamento direcionado a atender as necessidades desse excesso populacional.

A migração italiana torna-se maciça a partir de 1880. No início a maioria dos italianos que vieram para a América, mais precisamente para o Brasil, era originária do Sul da Itália, região mais pobre e onde a população não encontrava meios suficientes para sua sobrevivência. Conforme essas necessidades foram aumentando dentro do território italiano, os imigrantes que moravam no Norte da Itália também começaram a migrar.

Portanto, foram os problemas econômicos que desencadearam a emigração italiana para a América. O processo de unificação da Itália, após as guerras napoleônicas, deixou a agricultura em grandes dificuldades, e como a industrialização não conseguia empregar o mínimo de pessoas que fizesse com que a pressão demográfica diminuísse, e emigração foi a saída para que fosse possível alcançar uma melhoria no âmbito econômico e social da população em geral (IANNI, 1963).

Miséria! Esta é a verdadeira e exclusiva causa da emigração transoceânica entre 1880 e a Primeira Guerra Mundial [...]. A fuga a pé em pleno inverno, para chegar ao porto de embarque - Gênova - envolvia aldeias inteiras e podia assumir aspectos de verdadeira libertação, como notava, não sem certo temor um observador da época, De Kiriaki "Vão para a América como iriam à aldeia vizinha na festa do padroeiro, e vão em procissão, às vezes até o som dos sinos, quando não levam consigo estes, como aconteceu em uma aldeia em Treviso" (TRENTO, 1989 p. 30-31).

A situação da Itália na época era crítica. A produtividade era baixa e devido a guerra de unificação iniciada em 1861, já não se dispunha mais de terras para cultivar, forçando os agricultores a arrendar terrenos de outros para poder plantar e vender o excedente para sobreviver (CONSTANTINO, 1998). Além da pobreza, principalmente da população rural, juntava-se o fato da falta de educação (analfabetismo elevado) e as condições precárias de moradia. $O$ governo italiano, para diminuir as tensões sociais, recorreu à emigração, intensificando a propaganda para que a idéia da emigração atingisse a maior quantidade de pessoas possível. A esperança de "fazer a América" contagiava os italianos. Devido aos fortes laços familiares da cultura italiana, não viajava somente o chefe da família e assim, muitas famílias inteiras vieram para a América e para o Brasil. 
Nesse mesmo período, o Brasil necessitava de imigrantes devido a diminuição do estoque de escravos ocasionados por leis abolicionistas como a Lei do Ventre Livre e a Lei dos Sexagenários, implementadas no último terço do século XIX. Foi a partir de 1870 que o Brasil passou a receber os imigrantes para trabalharem nas lavouras de café. Com a abolição da escravatura, em 1888, o fluxo de emigração foi intensificado. Dessa forma, com o governo italiano "expulsando a pobreza" e com os fazendeiros paulistas necessitando de mão-de-obra, os interesses se cruzaram e ambas as partes passaram a financiar essa migração.

O Brasil então, a partir da segunda metade do século XIX, aparecia na rota das imigrações européias. Os imigrantes europeus, portanto, vieram substituir a mão-de-obra escrava nas plantações de café localizadas, principalmente, em São Paulo. Vendendo a sua força de trabalho mantiveram a produção dos cafezais no Brasil. A maioria desses migrantes era de origem italiana e se fixaram como colonos nas fazendas de café no estado de São Paulo. Para se ter uma idéia, em 1920, dos cerca de 1,5 milhões de estrangeiros no Brasil, mais de $1 / 3$ eram italianos (558, 4 mil), sendo que destes, mais de 70\% (398,7 mil) residiam no estado de São Paulo ( EMMI, 2008).

\section{AS ORIGENS, A CHEGADA E A INSTALAÇÃO DA FAMÍLIA OMETTO NO BRASIL}

Em 30 de setembro de 1853 nascia em Padova no Norte da Itália, Antônio Ometto, irmão mais novo de Girolamo Ometto, filhos de Marcário Ometto e Anna Marsari. Antônio morava com o irmão, que se tornou chefe da família após a morte dos pais. Viviam em uma casa no campo que media em torno $6.000 \mathrm{~m}^{2}$. Girolamo casou-se primeiro com uma moça chamada Pierina, e já tinha seis filhos quando Antônio Ometto casou-se com Caterina Biasio (FIGUEIREDO, 1998).

Apesar de proprietários de uma pequena porção de terra, a família era numerosa, a conjuntura da Itália não era boa, como já frisado, e a situação da família Ometto acompanhava o momento atual do país onde viviam. Em 1881 Pierina teve mais um filho e no dia 21 de julho desse mesmo ano nasceu Constante, primeiro filho de Antônio e Caterina.

O camponês italiano no final do século XIX tinha como preocupação somente o seu sustento e o de sua família. Cabia ao componente mais velho de cada família, normalmente o pai, comandar as ações da unidade de produção familiar, e sua decisão teria de ser acatada sem contestação (ALVIM, 1986). E assim, após o nascimento do segundo filho, uma menina que foi batizada com o nome de Carolina pelos pais Antônio e Caterina, em 1886, estes tiveram que sair da casa onde moravam com Girolamo. Havia muita gente para pouca terra. Antônio foi para Comuna de Mira, povoado localizado entre Padova e Veneza, e passou a trabalhar como mão-de-obra braçal.

Revista de Estudos Sociais | Ano 2014, N. 31, V. 16, Pag. 101 
Vivendo em uma situação precária e com incontáveis propagandas incentivando a emigração, a decisão de viajar para o Brasil foi apenas questão de tempo.

Em 1887, Martinho Prado Junior, fazendeiro paulista, fez uma viagem para a Itália, e montou um escritório em Gênova para servir como um crivo de emigrantes, onde dava preferência a agricultores com famílias formadas. Nessa experiência, Martinho Prado Junior revelou sua preferência aos italianos do Norte, pois segundo ele os imigrantes dessa região tinham maior propensão ao trabalho e a economia ${ }^{3}$ para que logo alcançassem a condição de proprietários de terra. A Sociedade Promotora de Migração, então presidida por Martinho Prado Junior, passou a contratar imigrantes italianos para trabalhar nas lavouras de café, pagando suas passagens e despesas de transportes desde a saída da Itália até as fazendas de café (GOMBINI, 2006).

Antônio da Silva Prado, então ministro de Estado de Negócios da Agricultura, Comércio e Obras Públicas e irmão de Martinho Prado Junior, fez um contrato com a Jácomo Nicolau de Vicenza \& Filhos, uma companhia de navegação para transportar 20 mil italianos do Norte da Itália para o Brasil. Em uma das viagens desse contrato em 22 de agosto de 1887, Antônio, Caterina e os filhos Constante e Carolina embarcaram para o Brasil no navio Roma, tendo como destino o Rio de Janeiro (CINTRA,1986).

Chegaram no dia 17 de setembro de 1887 e foram encaminhados para a Hospedaria da llha das Flores, no Rio de Janeiro. Permaneceram lá por quatro dias tendo seguido depois para a estação ferroviária onde embarcaram no trem da Companhia São Paulo \& Rio de Janeiro que tinha São Paulo como destino. Se estabeleceram na Hospedaria dos Imigrantes em São Paulo, local onde os contratantes escolhiam os futuros colonos para trabalharem em suas propriedades ou nas propriedades que representavam. Receberam do governo um auxílio em dinheiro de $48 \$ 000$ para cada adulto e $12 \$ 000$ para cada criança (CINTRA, 1986).

Antônio Ometto e sua família foram contratados para trabalhar na Fazenda Salto Grande, de propriedade do Barão de Indaiatuba, José Bonifácio do Amaral, no município de Amparo. Na propriedade havia uma colônia onde moravam outros trabalhadores que labutavam nas imensas plantações de café. Nessa colônia, Antônio Ometto e sua família receberam uma casa destinada aos empregados pois todas as famílias que trabalhavam nessa fazenda possuíam a sua (FIGUEIREDO, 1998). Amparo era uma cidade repleta de fazendas de café e quando a família Ometto lá chegou já haviam muitos italianos morando na cidade.

Enquanto os Ometto permaneciam trabalhando e economizando na Fazenda Salto Grande, no dia 13 de maio de 1888, foi proclamada a abolição da escravatura no Brasil e o papel do imigrante passava a ser fundamental para o desenvolvimento do país por meio do seu trabalho nas plantações de café, principal produto de exportação do país. Após a libertação dos escravos, o processo da imigração de povos estrangeiros para trabalharem nas lavouras

\footnotetext{
${ }^{3}$ Vale ressaltar que Robert Putnam em 1993, mais de 100 anos depois, chegou a conclusões semelhantes em sua obra Comunidade e Democracia: a Experiência da Itália Moderna.
} 
de café foi intensificado. Os italianos foram os imigrantes que desembarcaram no Brasil em maior quantidade e São Paulo era o principal destino (FURTADO, 1987).

Segundo Levy (1974), de 1872 a 1889 chegaram ao Brasil 322.591 imigrantes italianos. De 1890 a 1909 chegaram 690.365 imigrantes de mesma nacionalidade.

\begin{abstract}
Após a abolição, jamais houve falta de braços, seja nos cafezais de São Paulo, seja para a industrialização que ocorreu no Estado. Ao contrário, o rápido processo de expansão econômica sempre contou com larga oferta de braços, que veio, particularmente, pelo afluxo de imigrantes (KOWARICK 1994 p.15).
\end{abstract}

Com a intensificação da imigração para o Brasil, principalmente a de imigrantes vindos da Itália, Girolamo Ometto, irmão mais velho de Antônio Ometto, veio para o Brasil em novembro de $1889 \mathrm{com}$ a esposa Pierina e mais oito filhos: Virgínia, Marco, Pietro, Sílvio, Macário, Maria, Anna e Regina. Com uma família numerosa, Girolamo recebeu $384 \$ 000$ do governo, e juntando com o que já tinha trazido de sua terra natal, adquiriu uma parte da Fazenda Morro Grande, localizada em Piracicaba. Girolamo chamou para junto de si o irmão Antônio e sua família, que naquele ano já contava com um novo membro: José Ometto, nascido em 15 de abril de 1889, primeiro filho brasileiro de Antônio e Caterina.

Em Piracicaba nasceram mais quatro filhos, todos homens: Pedro, Jerônimo João e Luís. Nas novas terras, Antônio e Girolamo plantaram canade-açúcar, cultura que Antônio havia aprendido a cultivar em Amparo por meio de outros colonos italianos. A plantação de cana-de-açúcar não exigia muito capital e tinha retorno rápido. Faziam pinga e açúcar mascavo, tipo de açúcar que se fazia na região. O açúcar branco ainda vinha do Nordeste. Com o dinheiro Girolamo resolveu adquirir mais terras em Piracicaba, e para obter maior liquidez para o novo negócio, hipotecou as terras que eram de sua propriedade. Em meados de 1901, Girolamo faleceu e logo depois, já em 1902, também faleceu Antônio, vítima de uma apendicite. As dívidas ficaram a cargo dos filhos e viúvas. Caterina estava viúva e com sete filhos (CINTRA, 1986).

Venderam tudo e saldaram as dívidas. Caterina e os filhos permaneceram em Piracicaba e foram trabalhar na Fazenda São José, de propriedade do Coronel Juca Barbosa. Na fazenda havia plantações de café e de cana-de-açúcar. Outros colonos italianos também trabalhavam nesta fazenda. Constante, filho mais velho de Caterina aprendia a ler com esses colonos e de noite repassava aos irmãos, o que ajudava na diminuição de custos da família. Tudo o que era ganho era economizado com o fim de adquirir uma nova terra (FIGUEIREDO, 1998). Carolina casou-se com Felício Pavan e foi morar com ele nas dependências da Société dês Sucréries

Revista de Estudos Sociais | Ano 2014, N. 31, V. 16, Pag. 103 
Brésilienses, maior engenho de Piracicaba, empresa de capital francês, onde Felício era um dos colonos.

Em 1906, depois de quase cinco anos trabalhando para o Coronel Juca Barbosa conseguiram juntar dinheiro suficiente para comprar seis alqueires de terra em Piracicaba na Fazenda Água Santa. Era uma fazenda de café e, conforme os pés iam ficando velhos, os irmãos os cortavam e no lugar plantavam cana-de-açúcar. Nessa época, a diferença entre empregado e patrão era muito grande. Poder trabalhar para si e ter o lucro por inteiro no final da colheita era uma quantia monetária significativa se comparada com o que os trabalhadores ganhavam de salário trabalhando para outros. Assim, se poderia acumular uma quantia de capital de forma mais rápida e Caterina e seus filhos seriam capazes de investir em maiores quantidades de terras e assim, multiplicar os lucros.

Parte do que plantavam na fazenda tinha como destino a "Sucrérie", que era um comprador certo e o restante era destinado à fabricação de aguardente. Os negócios iam indo bem e Luís, o filho mais novo, e os netos foram designados a estudar. Luiz e Antoninho, filho de Constante, foram os primeiros a se formar; cursaram contabilidade. Os mais velhos ficaram ocupados pelo trabalho. Em 1911 a família comprou novas terras, vizinhas das que já possuíam, ampliando a fazenda. Com o aumento do patrimônio fundiário, os Ometto pararam de vender a cana para a Sucrérie, passando a destinar toda a produção para o alambique. As terras estavam somente no nome de Constante e José, e, por vontade de Caterina, elas foram divididas em seis partes iguais entre os irmãos (CINTRA, 1986). Nascia, assim, nesse momento, a empresa Irmãos Ometto \&Cia., embora esta tenha sido oficializada somente em 1932.

As compras de terra aconteciam conforme as oportunidades surgiam. Em 1918 uma forte geada caiu sobre os cafezais no Estado de São Paulo, queimando inúmeros pés de café. Foi essa a ocasião que os irmãos Ometto aproveitaram para expandir seus negócios. Compraram quatorze alqueires na Fazenda Aparecida, onde hoje está localizado o município de Iracemápolis, então distrito de Limeira e para lá foram Constante e José, os outros irmãos ficaram com Caterina. A partir de então, foram cada vez mais adquirindo terras vizinhas a essa propriedade, até que em 1924, houve a necessidade de todos os irmãos se fixarem na Fazenda Aparecida, para poderem arcar com compromissos assumidos tendo sido as terras em Piracicaba referentes a Fazenda Água Santa doadas para Felício Pavan e Caroline Ometto, pois o casal já possuía nove filhos e passava por grandes dificuldades (CINTRA, 1986).

Em 1932 os irmãos adquiriram a Fazenda Bela Vista, onde montaram a primeira usina de açúcar, ficando a mesma sob a administração de Pedro Ometto. Pedro, quando fazia tratativas para aquisição de equipamentos e máquinas para a usina, conheceu Mário Dedini, o primeiro fornecedor de máquinas para a Usina Bela Vista e para as demais que a família viria a adquirir. Em 1935 foi adquirida a Fazenda São João, em Araras, cuja administração ficou por conta de José Ometto. Todavia um trágico acidente deixou José sem sua perna direita, fazendo com que o filho mais velho dele, Hermínio, tomasse a frente dos negócios da fazenda em Araras e implantasse 
a Usina São João. Em 1937 a família comprou a fazenda Iracema, que possuía mais de 100 mil pés de café, e, na medida em que os mesmos foram envelhecendo, foram substituídos por plantação de cana-de-aççúcar que viabilizou a implementação da Usina Iracema. Ainda em 1937, também foi adquirida a Fazenda Costa Pinto, que deu origem a Usina Costa Pinto.

Poucos anos depois, no início dos anos 1940, os irmãos Ometto compraram a Fazenda Pau D'alho, em Jaú, e organizaram mais um empreendimento de álcool e açúcar, a Usina da Barra. Em 1950, montaram em Leme a Usina Santa Lúcia e em Pradópolis a Usina São Martinho. Um pouco antes em 1945, já haviam fundado em Américo Brasiliense a Usina Santa Cruz $^{4}$.

Os Ometto colaboraram muito para que o estado de São Paulo se tornasse o maior produtor de açúcar do país. O governo Vargas estimulou a produção de várias culturas diferentes da café, devido à crise de 1929, incentivando a diversificação. Para a cana-de-açúcar foi criado o Instituo do Açúcar e do Álcool (IAA), com o objetivo de controlar a qualidade do açúcar e incentivar a produção do álcool. Dessa forma procurou evitar a superprodução de açúcar mantendo os preços em alta. Com a Segunda Guerra Mundial, houve um aumento na demanda de álcool devido à limitação da importação de petróleo ocasionada pela guerra. São Paulo, já naquela época, era o maior centro consumidor de petróleo do Brasil e naquele momento aumentou significativamente o consumo de álcool. Para suprir essa demanda a produção foi intensificada e o IAA teve que autorizar a instalação de novas usinas no estado. Em 1951, São Paulo superou o estado de Pernambuco na produção de álcool e açúcar (TÁVORA, 2011). O expressivo patrimônio fundiário e industrial gerou significativo faturamento das empresas trazendo, por conseqüência, grande prestígio para a família. Os Ometto haviam formado um dos maiores conglomerados industriais do país e com isso passaram a desfrutar posição de destaque na sociedade e a ocupar cargos políticos - prefeitos e vereadores na administração das cidades onde estavam estabelecidas as suas usinas.

$\mathrm{Na}$ década de 1960, o governo militar implementou o Planos de Integração Nacional que tinha como um dos objetivos ocupar o "vazio demográfico" da Amazônia, fazendo com que muitas empresas fossem atraídas pelos significativos incentivos fiscais, principalmente os investidores oriundos de São Paulo, maior centro econômico do país. O grupo empresarial dos irmãos Ometto foi um dos muitos empreendimentos do centro-sul atraídos por esses incentivos e, em 22 de setembro de 1966, teve aprovado pelo governo federal o projeto referente à instalação da Agropecuária Suiá-Missú S/A, localizada no estado do Mato Grosso. Dentre os acionistas da empresa agropecuária amazônica da família figuravam Luiz Ometto, o mais novo dos irmãos, Orlando Chesini Ometto (filho de Pedro Ometto e Narcisa Chesini) e Hermínio Ometto (filho de José Ometto e Romana Belloni). As terras para formação da Agropecuária Suiá-Missu foram vendidas aos Ometto por intermediação de Ariosto da Riva, que ficaria depois conhecido como o último

\footnotetext{
${ }^{4}$ Informações sobre as Usinas nos sites: www.usinacostapinto.com.br; www.usinasantalucia.com.br; www.usinasantacruz.com.br; www.saomartinho.ind.br; e www.cosan.com.br.
}

Revista de Estudos Sociais | Ano 2014, N. 31, V. 16, Pag. 105 
bandeirante, por sempre estar em busca de novas terras em direção ao Oeste brasileiro.

Após vender as terras localizadas em São Félix do Araguaia, então distrito do município de Barra do Garças, em Mato Grosso, Ariosto da Riva foi para Alta Floresta, ainda mais para o Oeste, onde estabeleceu uma espécie de "Reforma Agrária Privada".

\section{A OCUPAÇÃO DO ESTADO DO MATO GROSSO}

A busca incessante por minérios valiosos levada a cabo pelos bandeirantes a partir do último terço do século XVI, fez com que surgissem rotas que adentrassem a floresta rumo ao Oeste do Brasil. Cuiabá foi uma das cidades que surgiram por meio da busca incessante das riquezas minerais, sobretudo o ouro e a prata. Com o descobrimento em 1719 de minas na região do rios Coxipó e Cuiabá, dava-se início a "ocupação" do atual Estado do Mato Grosso. Não demorou muito para que a curiosidade do governo português fosse aguçada e em 1748 a então Capitania do Mato Grosso passou a ser controlada mais efetivamente pelo governo português, pois, dois anos depois, com a ascensão do Marquez de Pombal, ficou diretamente subordinada ao novo Estado do Grão Pará e Maranhão sediado em Belém e comandado por Francisco Xavier de Mendonça Furtado, irmão do primeiro ministro português. Assim teve início a formação latifundiária da então capitania do Mato Grosso. $O$ governo português, para fazer valer a sua autoridade, ofereceu concessões de grandes porções de terras a alguns lavradores. Dava-se início a construção do poder local que comandava a capitania conforme as ordens do governo português. E assim foi até o fim do período colonial (SOARES, 1975).

No ano de 1956 a região passa a ter maior importância no cenário comercial devido a navegação no Rio Paraguai. Isso fez com que vários produtores do Oeste paulista e da parte Sul do Mato Grosso pudessem exportar seus produtos. A cana-de-açúcar, uma cultura de retorno relativamente rápido, e que requer poucos cuidados por parte do agricultor, teve um aumento significativo e conseqüentemente houve o aumento da produção e da exportação de açúcar, rapadura e aguardente. Essa rápida, porém significativa expansão teve que ser estancada durante a guerra do Paraguai, que começou em 1864. Após o término da guerra em 1870, as navegações no rio Paraguai foram retomadas e definitivamente o estado do Mato Grosso foi integrado ao sistema financeiro nacional como uma rota de exportação de produtos, sendo naquele momento, o látex o principal produto de exportação. $O$ aumento das exportações escoadas pela região fez com que houvesse uma valorização das terras aumentando o comércio de propriedades extensas, ratificando o modelo latifundiário na região (MORENO, 1993).

Com a diminuição da demanda pela borracha brasileira, o cultivo da erva-mate, iguaria muito consumida pela população indígena, se tornou a maior atividade econômica da parte Sul do Mato Grosso (atual Mato Grosso do Sul), fazendo com que a região recebesse uma população expressiva (SOARES, 
1975). A parte Norte do Estado, atual Mato Grosso, era povoada por pequenos agricultores e por tribos indígenas. O território não estava desocupado, mas a densidade demográfica era baixa.

Getúlio Vargas, que assumiu em 1930 a presidência do Brasil, por meio de um golpe de estado, tinha o objetivo de promover a integração nacional. A política de Vargas ficou conhecida como "Marcha para o Oeste". Esta política de integração nacional atendia aos interesses do grande capital. A expansão da industrialização requeria uma quantidade maior de matérias-primas e expansão do mercado consumidor. Com o incentivo da migração do excedente populacional do Centro-Sul do país para o Oeste do Brasil, se aumentaria a produção de matérias-primas e o mercado consumidor, e ainda se diminuiria a pressão que era exercida pelo contingente populacional.

As verdadeiras razões da Marcha para o Oeste eram a abertura de frentes fornecedoras de produtos alimentícios mais baratos para os centros urbanos emergentes e a contenção dos conflitos sociais já verificados em outras regiões do país, direcionando os excedentes populacionais para os vazios demográficos existentes (PESSOA, 1999 p.47).

Dessa forma, o governo incentivou a expansão do capitalismo para o Oeste, favorecendo os grandes capitalistas, fornecendo mão-de-obra, matériaprima e mercado consumidor. Nos anos 1950 a Companhia de Desenvolvimento do Mato Grosso (CODEMAT), passou a vender terras do estado para a iniciativa privada ${ }^{5}$, o que possibilitou a formação de latifúndios ao Norte do Mato Grosso.

Com a chegada da ditadura após o golpe militar em 1964, a política não foi diferente, os privilégios ao grande capital e as facilidades do governo estadual para a formação de latifúndios e exploração de mão-de-obra barata continuaram.

No governo militar, com a conjuntura econômica e política do Brasil na época, os planejamentos de "ocupação" e desenvolvimento do Estado do Mato Grosso passaram a abranger três âmbitos: o geopolítico, voltado para a distribuição de terras para efetivar a "ocupação"; o âmbito econômico, para fortalecer a economia nacional através da produção e consumo de bens; e o âmbito social no sentido de transferir o "excedente" populacional do Sul, Sudeste e Nordeste brasileiro para aquela região. Nesse contexto, os

\footnotetext{
${ }^{5}$ Essa foi a maior fonte de arrecadação do Estado do Mato Grosso na década de 50. Essa venda se estende até 1986.
}

Revista de Estudos Sociais | Ano 2014, N. 31, V. 16, Pag. 107 
diversos governos federais e estaduais estimularam a migração de gaúchos, catarinenses, paranaenses, paulistas, mineiros, capixabas e nordestinos para as regiões "desocupadas" do Estado do Mato Grosso (CAVALCANTE; FERNANDES, 2006 p.114).

Para atuar diretamente nas ações de expansão da fronteira agrícola em direção ao Oeste, o governo militar criou autarquias localizadas nas regiões atuantes, portanto, longe do centro político e econômico do país, para regulamentar a posse e incentivar os grandes capitalistas a investirem nas terras amazônicas e do Centro-oeste. Foram instituídas a SUDAM (Superintendência do Desenvolvimento da Amazônia), criada para substituir a SPVEA ${ }^{6}$ (Superintendência do Plano de Valorização Econômica da Amazônia), criada pelo governo Vargas em 1953 e a SUDECO (Superintendência do Centro-Oeste), criada em 1967.

O governo militar, por intermédio da SUDAM, estabeleceu o decreto de no58.895 de 20 de julho de 1966, que permitia e execução de uma política de incentivos fiscais, a qual determinava que o governo teria que arcar com $75 \%$ do orçamento do projeto para o estabelecimento da empresa e somente $25 \%$ ficaria a cargo do proprietário. O decreto ainda estabelecia que: 1) Os $25 \%$ referentes aos investimentos de recursos próprios do empresário poderiam ser contabilizados com a terra, ou seja, o Estado acabava por arcar com $100 \%$ da totalidade do projeto, pois quem propusesse um projeto agrícola teria que ter as terras para oferecer. 2) O capital investido pelo governo nas propriedades privadas era a fundo perdido, o empresário agrícola não teria que devolver 0 dinheiro ao cofres públicos.

A "Operação Amazônica" - como é conhecido o
elenco de leis, decretos e medidas que
instrumentalizaram a política da ditadura para a fronteira
amazônica - adicionou elementos fundamentais a esses
instrumentos, a saber: a) a inclusão na Amazônia, da
agropecuária entre os setores possíveis a serem
incentivados; b) a possibilidade do valor das terras poder
ser considerado recursos próprios dos titulares dos
projetos agropecuários. Ambas as inovações, deveram-
se à influência, já naquele momento, forte, de uma leva
de novos proprietários que se atribuíam o controle de
grandes extensões de terras no Sul e Sudeste do Pará e
Norte no Mato Grosso e Goiás [atual Tocantins]. E deram
nova características aos incentivos fiscais: eles são
agora endereçados à fronteira agrícola na medida em
que atrelam de forma indissociável o acesso ao filão dos
incentivos fiscais à propriedade de terras (COSTA, 1998
p.49).

${ }^{6}$ A SPVEA foi o órgão governamental responsável pela construção da Rodovia Belém-Brasília.

Ano 2014, N. 31, V. 16, Pag. 108| Revista de Estudos Sociais 
Nesse contexto foi instalada a Agropecuária Suiá-Missú S/A de propriedade da família Ometto, em São Félix do Araguaia, então distrito de Barra do Garça, constando como acionistas da empresa no momento da fundação: Luís Ometto (filho mais novo de Caterina), Orlando Chesini Ometto (filho de Pedro Ometto e Narcisa Chesini) e Hermínio Ometto (filho de José Ometto e Romana Belloni).

\section{A ATUAÇÃO DA FAMÍLIA OMETTO NA AMAZÔNIA}

A Agropecuária Suiá-Missú foi registrada na Inspetoria Comercial do Estado do Mato Grosso em 21 de novembro de 1962 e transformada em Sociedade Anônima em 16 de julho de 1965. Como as tentativas de plantação de café e cana-de-açúcar não se tornaram viáveis , o projeto encaminhado pela família Ometto para a SUDAM já visava a criação, recria e engorda de gado bovino de corte. Posteriormente seriam implementados abatedouros, câmaras frias e equipamentos para aproveitamento de resíduos dentro da própria fazenda.

O projeto compreendia a implantação e desenvolvimento de cinco núcleos: o núcleo sede, instalado em 1966, os núcleos Fontoura, União, Roncador e Xavantes, instalados em 1969, 1972, 1973 e 1975, respectivamente. Para tanto o empreendimento contava com uma área de 646.824 hectares dos 800.000 hectares que a área da fazenda possuía ${ }^{7}$. Este chegou a ter o status de maior latifúndio da América Latina ${ }^{8}$. As obras de infraestrutura previstas neste projeto eram: casa grande para gerência; casa grande para viajantes e hóspedes; casa grande para uso pessoal da administração e hóspedes; sete casas para o pessoal da administração; prédio para arquivo; prédio grande para: farmácia; escritório; armazém e almoxarifado; residência com 6 cômodos e mais quatro quartos com 12 camas e banheiros ao todo; barracão para abrigar máquinas e veículos; oficina mecânica; serraria; prédio para a Casa de Força; prédio para o alojamento de 50 pessoas (peões e vaqueiros); paiol; caixa d'água a 8 metros de altura para 15 mil litros; duas casas geminadas para trabalhadores; 16 currais; e por fim seis açudes.

Tudo foi previsto que ser construído até o fim de 1971 e seriam adquiridos, ainda no ano de 1966, para o início da criação de gado bovino: 186 touros, 2.000 vacas e 2.000 novilhas. Para tanto investimento, o repasse do governo ao Grupo Ometto foi de CR $\$ 7.878 .000 .000,00$ (sete bilhões e oitocentos e setenta e oito milhões de cruzeiros). Um montante de dinheiro

\footnotetext{
7 Segundo a matéria da Rede Brasileira de Justiça Ambiental "Suiá-Missú, Mato Grosso: Sob ameaças, os Akwe-Xavante retornam ao seu território", a propriedade tinha cerca de 1,5 milhões de hectares conforme o demarcado na época, segundo a pesquisa.

${ }^{8}$ Otávio lanni em sua obra Ditadura e Agricultura (1979), afirma que o maior latifúndio das Américas era o da Jarí Florestal Agropecuária, pertencente ao norte-americano Daniel Ludwig, proprietário da National Bulk Carriers, que estava localizada nos estados do Pará e do Amapá e tinha uma área de 3,5 milhões de hectares.
}

Revista de Estudos Sociais | Ano 2014, N. 31, V. 16, Pag. 109 
significativo que iria gerar apenas 80 empregos permanentes e um desmatamento de 108.mil hectares já no ano de 1966 para o estabelecimento do núcleo sede.

\section{Quadro 1 - Quadro de acionistas da Agropecuária Suiá-Missú em 1971.}

\begin{tabular}{|c|c|c|}
\hline Acionista & $\%$ & Posição familiar \\
\hline Cia Industrial e Agrícola Ometto & 2424,86 & $\overline{E-}$ \\
\hline Usina Santa Lúcia S/A & 24,86 & - \\
\hline Orlando Chesini Ometto & 4,75 & Filho de Pedro \\
\hline João Ometto & 4,02 & 6ํirmão \\
\hline João Guilherme Sabino Ometto & 3,83 & Filho de João \\
\hline Hermínio Ometto & 3,77 & Filho de José \\
\hline João Ometto Sobrinho & 3,44 & Filho de José \\
\hline Virgíno Ometto & 2,79 & Filho de Constante \\
\hline Dimas Cêra Ometto & 2,47 & Filho de Luiz \\
\hline Luís Antônio Cera Ometto & 2,47 & Filho de Luiz \\
\hline Ernesta Ometto Maurano & 2,35 & Filha de Luiz \\
\hline Izaltina Ometto Silveira Mello & 2,35 & Filha de Luiz \\
\hline Natalina Ometto Gonçalves & 2,35 & Filha de Luiz \\
\hline Odete Ometto Altério & 2,35 & Filha de Luiz \\
\hline Helena Ometto Moreno & 2,21 & Filho de Pedro \\
\hline Homero Corrêa de Arruda & 2,13 & Genro de Constante \\
\hline Luiz Ometto & 1,99 & $7^{0}$ irmão \\
\hline Nélson Ometto & 1,66 & Neto de Constante \\
\hline Orlando Ometto & 1,51 & Filho de Constante \\
\hline Antônio Ometto & 1,48 & Filho de Constante \\
\hline Olga Ometto de Toledo & 0,69 & Filha de José \\
\hline Noemy Ometo Corrêa de Arruda Guedes Pereira & 0,52 & Neta de Constante \\
\hline Homero Corrêa de Arruda Filho & 0,52 & Neto de Constante \\
\hline Gilberto Rüegger Ometto & 0,37 & Neto de José \\
\hline Luiz Carlos Moreno & 0,08 & Genro de Pedro \\
\hline Fernando Manoel Ometto Moreno & 0,08 & Neto de Pedro \\
\hline Ana Maria Ometto Moreno & 0,07 & Neta de Pedro \\
\hline Narcisa Chesini Ometto & 0,03 & Esposa de Pedro \\
\hline
\end{tabular}

Fonte: SUDAM, 1971

Em 29 de junho de 1971 o Grupo Ometto solicitou a SUDAM a aprovação de uma atualização financeira de seu projeto agropecuário, que, 
como mencionava o primeiro projeto, era de interesse da região devido a colaboração ao desenvolvimento econômico da Amazônia que o empreendimento proporcionava, e por esse motivo, estava "objetivando poder usufruir dos benefícios da legislação de Incentivos Fiscais para a Amazônia/71 "(SUDAM, 1971, p.1)

Como de costume na família Ometto, as propriedades eram divididas entre os familiares e já em 1971, o quadro de acionistas que no projeto original constava de somente três nomes, havia aumentado para 28 , sendo $50 \%$ do empreendimento controlado por duas pessoas jurídicas do Grupo e os demais $50 \%$ por vinte e seis membros da família Ometto, conforme quadro 1.

Das obras mencionadas, que deveriam estar prontas em 1971, foram construídas apenas: a casa sede; o prédio para o alojamento de funcionários; duas casas geminadas; caixa d'água; almoxarifado; e por fim 22 currais. Nesse novo projeto o governo federal repassou ao Grupo Ometto uma verba de CR \$390.000.000,00, mesmo com a Agropecuária Suiá-Missú já apresentando uma receita positiva com a venda de gado de corte.

Conforme o rebanho ia aumentando, crescia a necessidade de formação de novos pastos o que levou ao aumento da área desmatada e eclosão de conflitos. Ariosto da Riva, que se associou inicialmente aos Ometto, logo desistiu da sociedade e vendeu sua parte nas terras para o Grupo Ometto devido a conflitos com posseiros e índios.

Esses conflitos passaram a incomodar o Grupo Ometto. Ariosto procurou novas terras desocupadas, mais ao Norte do Mato Grosso, onde hoje está localizado o município de Alta Floresta. O Grupo Ometto fez o mesmo, vendeu suas terras a empresa Liquifarm Brasil S/A, depois de entrar em litígio com os índios Xavantes quando foram iniciar as obras para estabelecer o núcleo que levava o nome da tribo.

Tabela 1 - Balanço Financeiro da Agropecuária Suiá-Missú S/A no ano de 1971.

\begin{tabular}{l|r|r|r|r}
\hline \multirow{2}{*}{\multicolumn{1}{c|}{ Discriminação }} & \multicolumn{2}{c}{ Ano } & $\mathbf{1 9 6 9}$ & 1970 \\
\cline { 2 - 5 } & $\mathbf{1 9 6 7}$ & $\mathbf{1 9 6 8}$ & & $\mathbf{1 9 0 0}$ \\
\hline \hline RECEITAS TOTAIS & 360.000 .000 & 560.200 .000 & 578.400 .000 & 513.000 .000 \\
\hline Déficit Estrutural & - & - & - & - \\
\hline CUSTOS TOTAIS & 328.551 .000 & 420.004 .000 & 439.921 .000 & 474.187 .000 \\
\hline Custos Fixos & 222.872 .000 & 224.282 .000 & 224.962 .000 & 228.422 .000 \\
\hline Custos Variáveis & 105.679 .000 & 195.722 .000 & 206.959 .000 & 245.765 .000 \\
\hline Rendimento Financeiro & $\mathbf{3 1 . 4 4 9 . 0 0 0}$ & $\mathbf{1 4 0 . 1 9 6 . 0 0 0}$ & $\mathbf{1 4 6 . 4 7 9 . 0 0 0}$ & $\mathbf{3 8 . 8 9 3 . 0 0 0}$ \\
\hline \hline
\end{tabular}

Fonte: SUDAM, 1971

Revista de Estudos Sociais | Ano 2014, N. 31, V. 16, Pag. 111 
A igreja católica interferiu junto aos índios que eram transportados para outras terras em aviões e helicópteros militares. O Grupo Ometto, após a venda de suas terras, adquiriu 200 mil hectares na Serra do Cachimbo, montando a Agropecuária do Cachimbo S/A. A então Liquifarm Agropecuária Suiá-Missú S/A pertencia ao capital estrangeiro. A Liquifarm Brasil S/A, que detinha 99,99\% das ações da Liquifarm Agropecuária Suiá-Missú S/A, tinha como principal acionista a Liquipar S/A, que detinha $99,99 \%$ das ações da companhia. Esta última tinha como principais acionistas a Liquigás Holding Jersey Ltda. (51\%) e a Capitalsin International Ltd. (49\%), localizada em Nassau, Bahamas ${ }^{9}$. Consta no Processo SUDAM no 06149/74 que a empresa apresentou certidão negativa de aldeamento indígena na área do empreendimento, emitida pela FUNAl, não havendo, conseqüentemente, restrição à utilização das mesmas e, também, que a Prefeitura Municipal de Barra do Garças certificou a inexistência de posseiros na área da fazenda. Francisco Matarazzo Sobrinho foi o primeiro presidente da Liquifarm Agropecuária Suiá-Missú S/A.

Já na Agropecuária do Cachimbo S/A., localizada no então distrito de Matupá, pertencente ao município da Chapada dos Guimarães, possuía uma área de 207 mil hectares e novamente recorreu a SUDAM para estabelecer um projeto de criação de gado, sendo aprovado em 20 de setembro de 1974, obtendo o beneficio do incentivo fiscal de $\operatorname{Cr} \$ 76.837 .510,00$. O quadro acionário era formado por empresas pertencentes ao Grupo Ometto, conforme quadro 2.

\section{Tabela 2 - Quadro Acionário da Agropecuária do Cachimbo S/A em 1964}

\begin{tabular}{l|l}
\hline Acionista & $\%$ \\
\hline \hline Cia. Industrial e Agrícola Ometto & 30,0 \\
\hline Cia. Indsutrial e Agrícola São João & 30,0 \\
\hline Usina Santa Lúcia S/A & 16,5 \\
\hline Indústria de Produtos Alimentícios Piraquê S/A & 16,5 \\
\hline Usina Boa Vista S/A & 70,0 \\
\hline \hline
\end{tabular}

Fonte: SUDAM, 1974b

Transformando o quadro acionário de nome de empresas para nome de pessoas temos como principais acionistas da Cia. Industrial e Agrícola Ometto: Luiz Ometto (7ํㅜ filho), João Ometto (6ํ filho),Virgínio e Antônio Ometto (filhos de Constante). A Cia Industrial a Agrícola São João apresentava Hermínio Ometto e João Ometto Sobrinho (filhos de José) com principais acionistas. A Usina Santa Lúcia S/A, tinha como componentes do quadro acionário Inez Ometto Zancaner, Narciso Ometto, Almerinda Ometto Colombo e Maria Ometto Ferraz ( filhos de Jerônimo). A Indústria de Produtos

\footnotetext{
9 Em 1984 a Agip Petroli, que atualmente tem o Vaticano como maior acionista, se tornou acionista majoritária da Liquifarm do Brasil S/A, e em novembro de 2010, a Justiça deu como veredicto o direito de volta as terras aos índios Xavantes para a região. O Vaticano recorreu.
} 
Alimentícios Piraquê S/A possuía como acionistas os quatro filhos de Jerônimo mencionados na última empresa, mais Celso Colombo, marido de Almerinda. Por último a Usina Boa Vista S/A possuía o mesmo quadro acionário da primeira empresa mencionada, a Cia. Industrial e Agrícola Ometto.

A área para formação de pastos já no primeiro ano foi de 39.950 hectares. O rebanho em 1981 atingiu a quantidade de 65.783 cabeças entre animais puros e mestiços. Em 1983, a Agropecuária do Cachimbo S/A se torna Colonizadora Agropecuária do Cachimbo e o Grupo Ometto passou a lotear as suas terras para a formação de um centro urbano, que deu origem ao atual município de Matupá, fundado em 14 de setembro de 1984 pela família Ometto.

Matupá foi elevada a categoria de município em 4 de julho de 1988, através da Lei estadual ำ5.317 e o loteamento feito pelo Grupo Ometto foi protocolado no INCRA e foi previsto para ser implementado em três etapas que assentaria uma população de 300 mil habitantes na cidade sem edificações, sendo que, a partir desse contingente os prédios seriam liberados.

\section{CONSIDERAÇÕES FINAIS}

A família Ometto apresenta uma história de superação, tendo os pioneiros de sua família trabalhando nas lavouras de café e posteriormente em alambiques, origem do expressivo patrimônio material que conseguiram amealhar depois da chegada dos pioneiros da família no Brasil. Nessa trajetória há que se destacar o papel da matriarca Caterina Biasio, que ficou viúva com sete filhos e os criou repassando valores que contribuíram para 0 sucesso dos irmãos Ometto nos negócios agropecuários.

Na Amazônia a atuação do Grupo Ometto foi de intensa exploração da terra e de mão-de-obra. Adquiriram e reproduziram dezenas de milhares de cabeça de gado, e para tal desmataram centenas de hectares e, com a valorização das terras devido a expansão da fronteira agropecuária em direção da Amazônia nos últimos anos do século XX, motivou os Ometto a lotear suas terras. Atualmente o município de Matupá, no Norte do Mato Grosso, ainda está retalhado em lotes destinados a urbanização, esperando por possíveis investidores nas terras mato-grossenses.

O império do açúcar e do álcool continua em poder da família Ometto. A Usina São Martinho tem como presidente Nélson Ometto, filho de Antônio Ometto e neto de Constante Ometto, o filho mais velho dos irmãos Ometto e tem como acionistas as empresas João Ometto Participações S/A (sendo o quadro acionário formado por herdeiros de João Ometto) e Luiz Ometto Participações S/A (sendo o quadro acionário formado por herdeiros de Luiz Ometto).

A Usina São Martinho ainda comanda as Usinas Iracema, Boa Vista e Santa Cruz. A Cosan, empresa fundada para unir em um só patrimônio todas as outras empresas da família Ometto é presidida por Rubens Ometto Silveira

Revista de Estudos Sociais | Ano 2014, N. 31, V. 16, Pag. 113 
Mello, filho de Celso Silveira Mello e Izaltina Ometto Silveira Mello, neto de Pedro Ometto. Esta é a maior produtora de etanol do mundo e sua origem está na antiga Usina Costa Pinto, fundada pelos irmãos Ometto e hoje trabalha com as marcas Móbil e União. Fazem parte da Cosan a Usina São João, a Usina da Barra e a Usina Santa Lúcia.

Curioso é que, tendo os negócios da família em São Paulo predominantemente sempre tendo sido focados em plantação e beneficiamento de cana-de-açúcar, a Fazenda São João em Araras, uma das mais expressivas do Grupo, parece ter assimilado a vocação das fazendas dos Ometto na Amazônia, também se dedicando atualmente à criação de gado de corte.

\section{REFERÊNCIAS}

ALVIM, L. Brava Gente: Os Italianos em São Paulo. Brasiliense. São Paulo, 1986.

CAVALCANTE, M.; FERNANDES, B. Formação Territorial, Agronegócio e Atuais Mudanças na Estrutura Fundiária de Mato Grosso. Revista NERA ano9, n.8. Presidente Prudente, 2006.

CINTRA, M. João Ometto: Uma Trajetória de Vida. Ed. Marca D'água. São Paulo, 1986.

CONSTANTINO, N. S. O Italiano da Esquina: Imigrantes na Sociedade Porto-alegrense. ESTEF. Porto Alegre, 1998.

COSTA, F. A. Grande Empresa e Agricultura na Amazônia: Dois Momentos, Dois Fracassos. Novos Cadernos do NAEA vol.1 ㄲo1. Belém, 1998.

EMMI, M. Italianos na Amazônia (1870-1950): Pioneirismo Econômico na Amazônia. Edufpa. Belém, 2008.

FIGUEIREDO, M. A Visão de Hermínio Ometto. Comissão de Biblioteca de Araras-SP. Araras, 1998.

FURTADO, C. Formação Econômica do Brasil. Ed. Nacional. São Paulo, 1987.

GOMBINI, R. Corações Partidos no Porto de Gênova. Instituto de Estudos Avançados da Universidade do Estado de São Paulo. São Paulo, 2006.

HOBSBAWN, E. A Era das Revoluções. Paz e Terra. Rio de Janeiro, 1977.

IANNI, C. Homens sem Paz: Conflitos e os Bastidores da Emigração Italiana. Difel. São Paulo, 1963.

IANNI, O. Ditadura e Agricultura. Ed. Civilização Brasileira. Rio de Janeiro, 1979.

KLEIN, H. S. Migração Internacional na História da América. In: BORIS, F. (org.) Fazer a América. Edusp. São Carlos, 2000. 
KOWARICK, L. Trabalho e Vadiagem: A Origem do Trabalho Livre no Brasil. Paz e Terra. São Paulo, 1994.

LEVY, M. S. F. O Papel da Migração Internacional na Evolução da População Brasileira (1872 a 1972). Revista Saúde Pública, São Paulo, 1974.

REDE BRASILEIRA DE JUSTIÇA AMBIENTAL. Suiá-Missu, Mato Grosso: sob ameaças, os akwe-xavante retornam ao seu território. Acesso em 04 de Janeiro de 2010 <http://www.midiaindependente.org/pt/blue/2004/02/273552.shtml>.

MORENO, G. Os (dez) caminhos da apropriação capitalista da terra em Mato Grosso. Tese de Doutorado da Faculdade de Filosofia, Letras e Ciências Humanas da Universidade de São Paulo. São Paulo, 1993.

PARECER № 295/66-AT-STO. Projeto de investimento para ampliação de uma empresa pecuária, no Distrito de São Félix, Município e Comarca de Barra do Garças, Estado do Mato Grosso. SUDAM. Belém, 1966.

PESSOA, J. M. A Revanche Camponesa. Editora UFG. Goiânia, 1999.

SUDAM. PROCESSO № 02863/71. Colaboração Financeira dos Recursos oriundos do Artigo 1 $^{\circ}$ alínea "b" do Decreto-Lei no 756 de 11 de agosto de 1969. Belém: SUDAM, 1971.

SUDAM. PROCESSO № 03374/74. Colaboração Financeira dos Recursos oriundos do Artigo 1 alínea "b" do Decreto-Lei no 756 de 11 de agosto de 1969. Belém, SUDAM, 1974a

SUDAM. PROCESSO № 06149/74. Colaboração Financeira dos Recursos

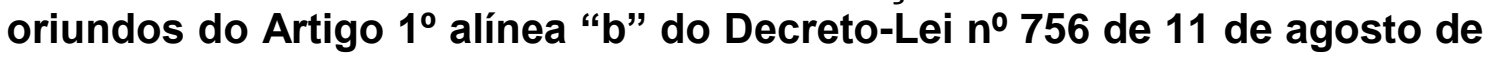
1969. Belém: SUDAM, 1974b.

PUTNAM, R. Comunidade e Democracia: a Experiência da Itália Moderna. FGV Editora, 2005.

SOARES, A. História da Formação das Fronteiras do Brasil. Ed. Conquista. São Paulo, 1975.

TÁVORA, F. L. História e Economia dos Biocombustíveis no Brasil. Texto para Discussão 89. Centro de Estudos de Consultoria do Senado Federal. Brasília, 2011.

TRENTO, A. Do Outro Lado do Atlântico. Nobel. São Paulo, 1989. 